\section{Mixed media policies of US federal agencies}

You cite two US government agencies that interact openly with the media (Nature 483, 6; 2012): the National Oceanic and Atmospheric Administration (NOAA) and the National Science Foundation (NSF). Yet these are rare exceptions in my experience as editor of FDA Webview and FDA Review.

Take the US Department of Health and Human Services (DHHS), which last September proclaimed a repressive media guidelines policy. All journalists are now referred to its press office, which permits access only to selected personnel and may monitor and record interviews (see go.nature.com/xczin6).

Another large US government entity, the Department of Justice, has gone even further. Barely a month after the DHHS move, it proposed a rule that directs federal law-enforcement agencies to respond to requests for particularly sensitive documents under the Freedom of Information Act "as if the excluded records did not exist" (see go.nature.com/gfd8pn).

Recent guidelines on openness from the NSF and NOAA are modest steps in the right direction - albeit on a tiny scale, given the size, scope and complexity of the US federal government.

James G. Dickinson Camp Hill, Pennsylvania, USA. jim@fdaweb.com

\section{China: a cultural shift for science}

I disagree that the ancient cultural influences of Confucius and Zhuang Zhou are to blame for the problems pervading China's academic research today (Nature 481, 411; 2012). Neither sage encouraged isolation or inhibited intellectual curiosity. I believe that China's problems are exacerbated by insufficient respect for these cultural traditions, which promote such values as objectivity and high moral standards.

China's scientists should be devoting themselves to the advance of research that abides by international scientific standards. Misconduct and other flaws undermine the Chinese government's increased investment in higher education and scientific research.

It is time for the research community in China to rekindle its respect for cultural traditions and to take responsibility for creating a healthy, transparent academic system.

Keqian Xu Nanjing Normal University, Jiangsu, China. xukeqian@njnu.edu.cn

\section{China: philosophers sparked good science}

Peng Gong misrepresents the thoughts of Chinese philosophers Confucius and Zhuang Zhou by suggesting that they hinder scientific advancement in modern China (Nature 481, 411; 2012).

Confucius encouraged curiosity and practice in teaching and learning. His thoughts are universal and timeless, and have influenced many other Asian countries including Japan, where sound science thrives.

Zhuang advocated harmony so that we could fulfil our essential connection with nature. This view is pertinent in today's China, where the environment and human health are being damaged by explosive and unbalanced development.

Moreover, Confucius, Zhuang and other ancient Chinese philosophers made significant advances in science, technology, medicine, mathematics, astronomy and architecture, with inventions such as paper and the compass having a large impact on civilization.

Jianxin Su Fujian University of
Technology, Fuzhou, China.

jianxinsu@gmail.com

Cheng Lu Newark, Delaware, USA.

\section{Work together to crack wildlife trade}

There is no single solution to monitoring illegal wildlife trade (L. F. Toledo et al. Nature 483, 36; 2012), which is widespread, adaptive and sophisticated. Extensive reforms are needed to expand government monitoring and reporting, and to include a wider range of detection strategies and non-government stakeholders (J. Phelps et al. Science 330, 1752-1753; 2010).

Government agencies are largely limited to regulating wildlife trade through monitoring and enforcement, mainly confined to checkpoints such as airports. More resourceful research strategies are crucial for keeping up with wildlife trading (see, for example, M. Gastañaga et al. Bird Conserv. Int. 21, 76-85; 2011).

Improving regulation will require broadening collaborations, for example through resource monitoring by local communities, engaging the private sector in pointof-harvest reporting, and forming partnerships with non-governmental organizations and academics. Local networks and expertise would encourage pooling of resources and give governments access to new techniques and methodological support.

Such cooperation would help to resolve taxonomic uncertainties and offer independent review of contentious trade decisions. This is especially relevant to countries where the technical and administrative authorities of the Convention on International Trade in Endangered Species lie within the same government institution.

Jacob Phelps, David P. Bickford, Edward L. Webb National University of Singapore, Singapore. jacob.phelps@gmail.com

\section{Colorado methane study not clear-cut}

As a partner of the US National Oceanic and Atmospheric Administration, we at Western Energy Alliance provided much of the data for the reported study on methane emissions from a natural-gas field in Colorado's Denver-Julesburg Basin (Nature 482, 139-140; 2012). However, uncertainties remain over the extent of methane leakage from these operations.

For example, this study (G. Pétron et al. J. Geophys. Res., in the press) relied heavily on data from mobile-laboratory samples taken in summer 2008, before regulations reduced emissions of volatile organic compounds to $90 \%$, and before low-bleed pneumatic devices were implemented to reduce methane emissions from the field. Much of the data were collected in an operating environment that no longer exists. Also, the venting you describe is at odds with industry practices.

The authors acknowledge that methane emissions from agriculture are of "comparable magnitude to the estimate from natural gas systems" in Colorado, but do not consider these.

Pétron et al. should have noted that methane readings were lower at the Boulder observation tower than at a tower in a Wisconsin forest that is far removed from significant industrial activity.

Kathleen M. Sgamma Western

Energy Alliance, Denver, Colorado, USA.

ksgamma@

westernenergyalliance.org

\section{CORRECTION}

A declaration of competing financial interests was omitted from the Correspondence

'Sugar: fruit fructose is still healthy' (Nature 482, 470; 2012). This has been added at http://go.nature.com/xudf1i. 